\title{
Review \\ Safety and Efficacy of Nail Products
}

\author{
Harleen Arora * and Antonella Tosti \\ Department of Dermatology and Cutaneous Surgery, Miller School of Medicine, University of Miami Hospital, \\ University of Miami, Miami, FL 33125, USA; Atosti@med.miami.edu \\ * Correspondence: haroramed@gmail.com; Tel.: +1-305-243-6704
}

Received: 27 June 2017; Accepted: 12 July 2017; Published: 15 July 2017

\begin{abstract}
Over the past several decades, the commercialization of nail cosmetics has increased. From nail polishes to artificial nails, different methods of nail beautification have become popularized. However, the impact of these products remains largely unknown. Governments have passed legislation in attempts to regulate nail cosmetics, but these regulations may not be adequate and are difficult to enforce. Knowledge of the safety and efficacy of nail products remains limited due to the relative dearth of literature published on the topic. This review serves to summarize and interpret the data available regarding common nail products and their safety and efficacy. Nail products such as nail polish, nail polish removers, and artificial nails have shown to have some adverse effects through case reports and studies. Harmful substances such as toluenesulfonamide-formaldehyde resin and methacrylates have been identified in commercial nail products, leading to several adverse effects, but in particular, allergic contact dermatitis. Exposure to substances such as acetonitrile found in removers may have more toxic and caustic effects, especially if ingested. In addition, for nail technicians there are negative effects linked with occupational exposure. Compounds used in nail products may become aerosolized and lead to asthma, eye and throat irritation, and even neurocognitive changes.
\end{abstract}

Keywords: nail care products; safety assessment; efficacy evaluation; nail disorders

\section{Introduction}

Nails, the protective structures we used for centuries as survival tools, have over the years become an accessory for beautification. Within the past few decades, products for cosmetic care of nails have grown on the market. From nail hardeners to nail polish to artificial nails, more and more products to enhance the cosmetic appeal of nails are being commercialized. There have been efforts by United States and European countries to regulate the quality of nail cosmetics. The United States Food and Drug Administration (FDA) instituted the Federal Food, Drug, and Cosmetic Act to do so, while the European Union Commission has instated Cosmetics Regulation No. 1223/2009. These regulations require that manufacturers and distributors provide ingredients and safety information of cosmetic products. The FDA's Federal Food, Drug, and Cosmetic Act defines a cosmetic product, provides regulation for adequate labeling of products, and even restricts compounds that have established adverse effects. Additionally, it requires conspicuous warning statements on products with potential health hazards and on products whose safety has not been determined [1]. The European Union (EU) has similar regulations in place and even requires a product information file documenting safety and manufacturing information to be made for each cosmetic item placed on the market. In 2004, the European Community Cosmetics Directive was passed, mandating that ingredients of all cosmetic products be published on the products [2]. With regards to cosmetic allergies in particular, both United States and European law restricts the usage of certain allergens given sufficient patch test data and literature publication [2]. Furthermore, EC Regulation No. 1223/2009 instated a "cosmetovigilance" system to create a systematic network of communication to report serious undesirable effects of 
cosmetics. Under this, the severity of adverse effects are analyzed and are reported to the distributors as well as competent authorities nation-wide and in the EU [3]. The FDA has a system in place known as the Voluntary Cosmetic Registration Program, which allows them to evaluate cosmetics on the market. The FDA also has the Cosmetic Ingredient Review Expert Panel, which is an industry-funded panel of scientists and experts who assess cosmetic products for ingredient safety [4].

These legislations and actions certainly help regulate cosmetics to an extent, but there are downfalls to these legislations. For instance, although legislation adapts to newly identified cosmetic allergens, there is often a long period of time between allergens being identified and action being taken to restrict usage of those allergens. For instance, the failure of the EU to appropriately regulate and halt the use of methylisothiazolinone in leave-on cosmetics, despite it being deemed unsafe [5], has been documented. Due to the improper and delayed enforcement of restrictions, more consumers continued to be sensitized to this compound which had been classified as an allergen. Furthermore, although steps are taken to restrict allergens based on literature, in the case of nail cosmetics and products, the evidence-based literature remains lacking. Therefore, animal studies are taken into consideration in the FDA's Cosmetic Ingredient Review. The EU's EC Regulation No. 1223/2009, however, regulates and largely prohibits animal testing for ethical reasons [6]. In addition, with the advent of online shopping, it is now very easy to access and import products from other countries, where regulation of cosmetic products may not be as stringent, leading to increased exposure to harmful ingredients. Therefore, there is little clarity about safety and efficacy of cosmetic products, and in particular nail cosmetics. This paper serves to review and interpret the data available for common nail products with respect to their safety and efficacy.

\section{Methods}

A total of 92 trials and case reports pertaining to the safety and efficacy of nail products were included in this review. Articles were collected through Pubmed and Cochrane databases with the following key words: nail care products, nail product safety, nail product efficacy, nail disorders, nail polish remover, nail glue remover, nail hardener, nail polish, artificial nails, acrylic nail, nail primers, nail moisturizer, trace elements nail cosmetics, heavy metals nail cosmetics, acetonitrile nail, formaldehyde nail, methacrylate nail, phthalate nail, and toluene nail. Inclusion criteria for this review: 1) studies or reports related to finger or toe nails 2) studies or reports about products (oral or topical) aimed at enhancing the cosmetic appeal of nails 3) studies or reports on efficacy and/or safety of defined nail products 4) studies on safety of individual ingredients in defined nail products 5) original studies only 6) human studies 7) articles in English or translated to English. Review articles, articles pertaining to cosmetics without safety or efficacy assessment, articles about medical treatments as opposed to cosmetic products, and articles regarding nail disorders without connection to nail products were all excluded except for ancillary supportive information. Expert reports on safety of ingredients and United States and European Union cosmetics regulations were also included for supportive information. Clinical trials, case reports, and board safety assessments were included.

\section{Cosmetic Nail Products}

Several nail cosmetic products exist on the market. However, the most studied products include nail polish, artificial nails, and nail polish remover. The safety of these and other products, as well as the occupational exposure to these products are discussed below.

\subsection{Nail Polish}

\subsubsection{Introduction}

Nail polish is one of the primary forms of nail beautification. Also known as nail varnish, enamel, or lacquer, nail polish has three main types [7]. The first is the basecoat, which serves the purpose of creating a smooth and uniform layer upon which the pigmented nail polish may be applied. 
The second is the pigmented nail polish, itself. The third is the aftercoat, which is applied on top of the pigmented nail polish to provide fortification against chipping as well as an added sheen. Nail polish often contains the following components: a film former, a plasticizer, a thermoplastic resin, a solvent-extender, pigment, and possibly a suspending agent [7]. The film former is often composed of nitrocellulose. The plasticizer, often dibutyl phthalate, serves to enhance adhesion and provides flexibility [7]. The thermoplastic resin, often toluene sulfonamide-formaldehyde, improves adhesion, hardening, and gloss [7]. The solvent extenders allow the components of the nail varnish to remain in a liquid form, and compounds used are usually ethyl acetate, isopropyl alcohol, butyl acetate, or toluene. Finally, the pigment component may be highly variable and may include elements such as iron oxides, color lakes, and mica [7]. The pigment may be organic or inorganic, although inorganic compounds must have low heavy-metal content [8].

\subsubsection{Findings}

A variety of adverse effects have been noted due to nail polish use. The use of nail polish has been linked to yellow-orange discoloration of the superficial nail, for instance [7]. Due to dyes in the nail varnish, particularly D\&C (drug and cosmetics colors) Red No 6, 7, and 34 and FD\&C (food, drug and cosmetics colors) Yellow No. 5 Lake, the keratin in the surface of the nail from the cuticle to the tip may become stained. This discoloration usually resolves within two weeks of removal of nail polish if the polish was left on for about a week. Longer use may lead to deeper penetration of the dye and discoloration that will only resolve with growing out of the nail [9]. In addition, keratin degranulation may occur in the process of repeated application, binding, and removal of nail polish to the nail plate. This degranulation and exfoliation of the nail plate may present as pseudo-leukonychia, with white patches and linear markings along the nail [10]. This discoloration of the nail may be mistaken for superficial white onychomycosis [11].

The most studied adverse effect, however, is allergic contact dermatitis (ACD) due to the different components of the enamel. In 1997, a woman presented with dermatitis of the hands, showing contact sensitivity to toluenesulfonamide-formaldehyde resin (TSFR) present in the nail varnishes she used. Dermatitis resolved with abstinence from these nail varnishes. However, upon application of a new nail polish, the patient once again developed a dermatitis, which this time was shown to be sensitivity to nitrocellulose [12]. No other literature was found to suggest sensitivity to nitrocellulose and the compound has been deemed safe according to the Cosmetic Ingredient Review Expert Panel [13]. However, reactions to toluenesulfonamide and formaldehyde have been documented with regards to nail polish, artificial nails, and other nail products [14-16]. For instance, de Groot et al. found that out of 119 patients patch tested for allergens in cosmetic products, 16 exhibited reactions to nail lacquer or hardener, with the most prominent patch test reaction being to TSFR [17]. Cases have described eczematous reactions on the face, as well as extensive reactions including dyshidrosiform blisters on the hands [18]. One study identified 14 females who tested positive for allergy to TSFR after presenting with extensive facial dermatitis (especially periorbital and perioral), without paronychium. All women admitted to the use of nail polish and/or nail hardener within the recent months or years [19]. A pediatric case was even reported, with a four-year-old girl who developed eyelid dermatitis and worsening of established flexural atopic dermatitis. Patch test was positive for tosylamide/formaldehyde resin found in the little girl's nail polish [20], and her condition improved with discontinuation of the nail polish. This case, in particular, suggests that sensitization to compounds in nail products may not only cause new allergic reactions along the hands and eyelids, but may also exacerbate pre-existing atopic dermatitis.

Many of the above studies emphasize the possibility of extensive distal allergic reaction to nail products without local adverse effects, likely through hand transfer. In fact, one study evaluated the allergic cause of periorbital eczema in 609 patients and nail varnish was found to be the contributing factor in $4 \%$ of cases [21]. Phthalates, although not largely linked to ACD, are chemicals with harmful systemic effects that are present in nail polish. A positive correlation has been shown between frequent 
nail polish use and the concentration of phthalate metabolites detected in the urine and serum of 33 women [22], suggesting that nail polish use might contribute to systemic buildup of phthalates and their subsequent negative effects.

Allergen metals have also been identified as components of nail polish, although their use is limited in certain countries. Nail polish bottles may, in fact, contain small metal beads that function to better mix the nail polish. A study was conducted by Sipahi et al. to analyze the concentration of allergen metals in nail polish bought in Istanbul, Turkey. Using an atomic absorption spectrometer, it was found that all samples contained at least two allergen metals. Over $1 \mu \mathrm{g} / \mathrm{g}$, the target value of allergen metals in a sensitive population, of the metal in question was found in $97 \%$ of products with nickel, $96 \%$ of products with chromium, and $54 \%$ of products with cobalt [23]. However, the systemic exposure dosage (SED), the amount of a cosmetic substance expected to enter the bloodstream per $\mathrm{kg}$ and per day, was negligible. Although the risk assessment of the cosmetic products was low, the concentration of allergen metals topically in contact with the skin and nails was still significant enough to extrapolate them as a probable cause of contact dermatitis commonly associated with these products [23].

Adverse allergic reactions associated with nail polish cannot only cause significant distress cosmetically and medically, but also psychosocially. In fact, one study evaluated the socio-medical consequences of dermatitis due to allergy to TSFR and the patients' own nail polishes. Nine patients had to request sick leave, four patients were hospitalized due to severe dermatitis, and two others changed their jobs entirely, thinking that their work was the source of their illness [24].

In addition to the direct effects of nail polish, some indirect adverse effects have been studied as well. In a study comparing natural nails without polish against freshly painted nail polish and chipped nail polish worn for greater than four days, Wynd et al. found that a statistically greater number of bacterial colonies were found on fingernails with old chipped nail polish on the hands of OR nurses after hand cleaning [25]. This suggests that old nail polish may be a vector for increased bacterial spread, which should be taken into account in healthcare and sterile settings. Another study analyzed the ability to achieve an accurate pulse oximeter read for nails with nail polish (colors: clear, brown, black, and brown) and acrylic nails, with normal fingernail as a control. The study concluded that clear and red nail polish as well as the acrylic nails all allowed pulse oximeter reads that were not statistically different from the control mean [26]. However, black and brown nail polish did not allow pulse oximeter reads in $12 \%$ and $64 \%$ of patients respectively and those that did, had a value reported that was statistically different from the control mean [26]. This suggests that darker nail polish color may distort oxygen saturation readings, which should be taken into account in hospital settings.

No studies could be found evaluating the efficacy of nail polish for cosmetic value, in particular. However, one study evaluated a positive secondary effect of nail polish usage. For instance, a film of opaque nail enamel can provide photoprotection to nails with an SPF of 500 or greater, especially when two coats of a dark opaque color are applied [27]. Therefore, the application of nail polish can be beneficial in patients whose nails have an increased susceptibility to sun damage, such as those taking chemotherapy drugs.

\subsubsection{Discussion}

No randomized control trials and few studies have been done to evaluate the safety and efficacy of nail varnish; most of the data available on this topic is in the form of case reports. Based on these reports, the major adverse effect of nail polish has been recorded to be allergic contact dermatitis, which may be localized to the ungual and periungual region or appear more diffusely along the face, chest, and arms. One of the most studied allergens which has been associated with nail polish is TSFR. Despite demonstrable allergies to TSFR, the United States FDA has not banned the compound, instead recommending caution and careful reading of ingredient labels before purchasing formaldehyde-containing cosmetics if one has evidence of allergy [28]. 2015, Europe's Scientific Committee on Consumer Safety (SCCS) supported the use of formaldehyde in nail hardeners 
and cosmetics at the maximum level of $2.2 \%$ as opposed to the previous $5 \%$ in order to increase safety in light of recent reports [29]. This new standard will hopefully aid in reducing sensitization and allergy to formaldehyde-containing resins while still maintaining the hardening and adhesion capabilities of these compounds. Acrylate allergies have also been detected in nail polish-users in some cases $[18,30,31]$. However, in those cases, the women studied also admitted to the usage of artificial nails, which have been more associated with acrylate sensitization.

Phthalate-use as plasticizers have been limited in Europe. Due to the possible carcinogenicity and birth defects implied by animal studies, use of dibutylphthalate and diethylhexyl phthalate in nail products has been restricted [32]. The US FDA, on the contrary, has not restricted phthalates due to the lack of definitive evidence of toxicity in humans, the low concentrations at which phthalates are used (the presumable exposure through nail polish is calculated to be less than the $50 \mathrm{mg} / \mathrm{kg} / \mathrm{day}$ that has been deemed the "no adverse effect level"), and recent data which shows that phthalate use in cosmetics has significantly decreased in the US [33]. This decision by the FDA was based on analysis by the Cosmetic Ingredient Review Expert Panel. However, the data cited to make their decisions was largely based on animal trials and case reports [33]. More structured studies and reviews about the short and long term safety of these chemicals in humans must be done in order to allow for better and more informed legislation, as well as less morbidity with use of these compounds.

Some secondary positive and negative effects of nail polish-use were gleaned from published studies: nail polish may become a source of bacterial colonization [25] and may also interfere with pulse oximetry readings [26], but nail polish may also help provide sun protection for patients with nails susceptible to sun damage [27]. However, no studies could be found to demonstrate the efficacy of nail polishes, making this an area which should also be further studied.

\subsection{Artificial Nails}

\subsubsection{Introduction}

Artificial nails are often used to extend the length of a person's original nail or for longer-lasting adornment of the nails. Many types of artificial nails exists. A whole or the tip of a preformed plastic nail may be glued to the existing nail, either in a salon or at home with a kit [34]. They may be removed with nail polish or nail glue remover. Another category of artificial nails is sculptured nails, which includes acrylic nails and photobonded gel nails [34]. Acrylic nails use a combination of a powdered polymer and a monomer liquid which are mixed upon the nail plate and then allowed to polymerize and harden. Natural light and an organic accelerator such as benzoyl peroxide may help facilitate this reaction. In the process of hardening, these nails may be sculptured into the desired length or shape [34]. The monomer used in this reaction is usually a methacrylate monomer. The use of methyl methacrylate (MMA) was rather common initially, but due to severe cases of contact dermatitis associated with this compound, its use was restricted in the US and Europe. Products with 100\% MMA monomer may no longer be used in the United States and many products with $>90 \%$ MMA were recalled in Europe [35,36]. Now, other methacrylate monomers such as ethyl methacrylate (EMA), ethyleneglycol-dimethacrylate (EGDMA), hydroxypropyl methacrylate (HPMA), and 2-hydroxyethyl methacrylate [33-35]. The powdered polymer is usually polymethyl methacrylate [34].

Gel nails are a newer fashion trend whereby the gel nail varnish is applied like normal nail polish, but then is allowed to polymerize through photobonding under a light source, usually ultraviolet (UV). Gel nails may require the application of several layers of colored or glossy layers, each layer needing to be polymerized under the UV light [34]. The lights used for nail curing now come in two varieties: UV lamps and light-emitting diode (LED) lamps. UV lamps are still more used than LED light, which tends to be more expensive. UV lamps emit mostly UVA rays, meaning that the light has a wavelength ranging from 100 to $400 \mathrm{~nm}$, with much of it being between 315 and $400 \mathrm{~nm}$ [37]. LED lamps have more targeted wavelengths between 350 and $450 \mathrm{~nm}$. Since LED light is more targeted, it allows for faster curing of gel nail polish, but only in polishes with LED-specific photoinitiators [38]. 
Gel nails may be obtained at a nail salon, but home kits are also available [7]. Home kits often contain: nail cleaner and nail file, as well as a primer solution, the gel nail polish, and a brush to apply the components [39]. A UV or LED lamp is also bought with the kit in order to cure the polish at home. Similar to a gel manicure at a salon, the consumer files and primes the nails. They then apply the gel coat and place their hands under the light to cure the polish [39]. This step may be repeated several times, till the consumer is content with the aesthetics of the manicure. Gel nails, similar to acrylic nails, contain substances such as ethyl cyanoacrylate and polymethyl methacrylate monomers [34]. All types of artificial nails require nail glue for application. The main components of nail glue are usually ethyl cyanoacrylate, hydroquinone, or organic sulfonic acid [34].

\subsubsection{Findings}

With regards to artificial nails, the main documented adverse effect has been allergic contact dermatitis, particularly to methacrylate monomers. As early as the 1940s and 1950s, cases of ACD due to acrylic nails were noted [40,41]. Findings such as paronychia and subungual swelling, severe pruritus, nail dystrophy, and scaling/vesicular dermatitis were noted. In one case, a "moth-eaten" appearance of the nail was described with slight separation of the nails from the nail bed [41]. In these older cases, acrylic monomers were suspected to be the offending agent, however the specific monomers could not be confirmed. Now, as patch testing has become more utilized as a diagnostic method for ACD, and as patch test panels are more discerning for particular monomers, specific allergens within artificial nail compounds may be isolated.

MMA is well-documented as a sensitizing monomer, causing severe allergic reactions including neuropathy and permanent fingernail loss [42]. Its use in high concentrations has been phased out in nail products, and other methacrylate monomers have been used in its place because they were thought to be safer [35]. However, sensitization to these other monomers through acrylic nails and gel nails has also been widely documented among both consumers and nail technicians. For instance, Le et al. [43] reported about three nail technicians who experienced hand dermatitis consisting of spreading pruritic rashes and painful fissuring of the skin. All these patients began applying acrylic and gel shellac nails to customers within the past year, and tested positive to monomers such as MMA, 2-HEMA, HPMA, EGDMA, ethylacrylate (EA), and triethylene glycol diacrylate (TREGDA) [43]. Cravo et al. [44] reported four cases, two women who were customers and two women who were both customers and beauticians. Three of the women developed periungual and hand dermatitis and reacted positively to HEMA and HPMA on patch test, while one beautician developed only eyelid dermatitis and reacted positively to TREGDA [44].

Many cases of localized paronychia, nail dystrophy, onycholysis, pruritic vesicular to lichenified scaling plaques of eczema, and fissuring along the hands have been reported, with patch-test results revealing sensitivity to the aforementioned monomers [18,31,45-52]. Onycholysis and subungual hyperkeratosis may also be manifestations of allergies to sculptured nails, and may be difficult to distinguish from nail psoriasis or onychomycosis $[47,53]$. In addition to these findings, paresthesias [34,42,54] and nail infection [34], likely superinfection of eczematous tissue, have been reported concomitant with dermatitis. More distal findings have been reported as well, likely due to hand transfer-related contact allergy or occupational exposure. The face, and particularly the eyelids, are commonly involved [21,31,41,44,48,51,54,55]. A case of cheilitis and lip edema in the setting of contact with UV-cured gel nails was reported. Only mild erythema of the periungual region was evident on the hands, but the patient had a positive reaction to HEMA, HPMA, EGDMA, and the gel polish color layer on patch test [56]. To subvert methacrylate allergy associated with photobonded nails, some companies have released "hypoallergenic" gel compounds which claim to be free of acrylates. However, cases have been reported of women with patch test-confirmed allergies to gel nails, who also reacted to hypoallergenic gel resin despite their claim of containing no acrylic compounds [45]. Similar ACD has also been reported as reaction to ethyl cyanoacrylate in nail glue used for artificial nails [30,34]. 
Some trends have also been noted with respect to morbidity in nail salon workers. An epidemiologic study showed that 21 of 908 patients who tested positive for allergy to acrylates such as MMA and 2-HEMA used nail-related cosmetics and 53 patients had exposure through employment at nail salons [57]. A retrospective study reviewed 87 patients who worked as nail cosmetologists and found that $47.1 \%$ of these patients reacted to at least one methacrylate, with the most common being 2-HEMA, 2-HPMA, and HEA [58]. Furthermore, in studying 55 females with exposure to artificial nails as consumers and in the workplace, Lazarov described that distant sites such as the forearms, the dorsal hands and fingers, and the face and neck, were more often involved in occupational ACD. Women with occupational exposure also tended to have more chronic dermatitis, although lichenified and psoriasiform dermatitis were also identified [52]. The distribution of eczematous lesions was echoed by DeKoven et al., however periorbital, facial, neck, lower extremity, and dorsal foot eruptions were found to be significantly less common than eczema of the dorsal hands, fingers, and forearms [59]. The most common allergens identified were 2-HEMA and 2-HPMA with over one-fourth of the patients also positively reacting to ethyl cyanoacrylate in the artificial nail glue [52]. Worsening of pre-existing asthma, new-onset asthma, and rhinitis [50] in nail technicians has also been observed. Two women who were sensitized to methacrylate monomers, both developed cough, rhinitis, wheezing, and shortness of breath, especially during exposure to sculptured nails at work [60].

Methacrylates also tend to have a high degree of cross-reactivity. Methacrylates are used not only in nail adornment, but also in dentistry, orthopedics, etc [49]. Once one is sensitized to methacrylates through one means, for instance exposure through acrylic nails, hypersensitivity reactions may develop when exposed to methacrylates in another setting, such as in a dental crown. This cross-sensitivity has been reported in cases. For instance, a dentist with decades of experience developed dermatitis after the application of acrylic nails with MMA monomer [61]. Her dermatitis resolved after removing the artificial nails, but returned when she resumed her work in dentistry and was exposed to methacrylate monomers at work [61]. Another unique case of cross-reactivity has been reported. A woman with extensive history of sculptured nails use developed periungual ACD due to methacrylate sensitivity [62]. She later developed erythema, swelling, and pruritus of the mouth and lips after having a temporary crown placed on one of her molars, showing cross-sensitivity to methacrylates in dental equipment. She also later developed a pruritic papulovesicular rash along her vulva, perineum, and inner thighs after using incontinency pads which had polyacrylates listed as an ingredient [62].

Concerns have also arisen relating to UV-cured gel nails in particular. Not only can the components of the gel nail lacquer be potentially allergenic, but the exposure of the hands to UV light in the process of photobonding may be associated with increased risk of skin cancer. Two cases were reported of females with an extensive history of UV nail light exposure who developed squamous cell carcinomas (SCC) of the hand [63]. One patient with a 15-year UV light use history developed an in situ SCC of the dorsum of her hand, while another patient who had used UV light eight times within the past year developed a series of four SCCs on her bilateral hands [63]. The hands are a location prone to accumulation of UV damage and, although confounding factors such as sun exposure history and genetics should be taken into account, this may suggest an association between UV nail light and SCCs. Subsequently, several studies tried to quantify the UV irradiance from UV nail lamps to determine their carcinogenic potential. In one study, the UV nail irradiation was compared to the UV dose delivered by narrow-band UVB light and it was determined that well over 10,000 ten-minute sessions of UV light to the nail plate would be needed to be equivalent to the UV exposure with one course (15-30 treatments over 5-10 weeks) of narrow-band UVB [64]. In another study, the UVA irradiance was found to be variable according to the brand of the UV light used and hand placement under the light. They also asserted that UVA exposure at each individual manicure visit is not enough to cause significant DNA damage [65]. However, the potential for carcinogenesis increases with the time spent under the UV light and damage is accumulated with multiple UV nail light visits. The authors determined that, depending on the light and the time spent under it, anywhere between 8 and $208 \mathrm{UV}$ nail light visits would be needed to reach the $600 \mathrm{~kJ} / \mathrm{m}^{2}$ threshold energy density to 
cause DNA damage [65]. Yet another study determined that the total energy nails were exposed to during the recommended curing time for UV light was between 285 and $386 \mathrm{~J} / \mathrm{m}^{2}$ which is equal to the day-long recommended irradiation limit for outdoor workers [66]. These studies suggest that, over time, UV nail light exposure has the potential for harm.

Other localized negative effects have been noted with artificial nails. For instance, distal nail plate thinning known as "worn-down nail syndrome" has been described as a combination of chemical insult from acrylic nails and mechanical insult from nail filing [67]. One study imaged with electron microscopy and obtained an elemental analysis of a healthy fingernail versus a fingernail that been exposed to synthetic nails and acrylic glue. Compared to the flat, uniform appearance of a healthy nail, the exposed nails were rough with globular areas [68]. Furthermore, elemental analysis revealed that nail glue causes degradation of disulfide bridges in the nail matrix, effectively destabilizing the matrix and causing roughness and loss of uniformity. The glue also diminished the amount of silicon and aluminum in the nail, decreasing the brightness and hardness of the nail [68].

Another concern with artificial nails is their potential flammability. Arnaout et al. [69] reported a case of 64-year-old female whose acrylic nail caught on fire after being in proximity to her lit cigarette. Although the patient put out the fire, the acrylic nail burned to completion, causing a full-thickness burn along her thumb which needed debridement and reconstruction [69]. In addition, three cases were reported where pediatric patients had experienced full thickness burns on the lower extremities due to accidental spillage of nail glue for acrylic nails. The glue, in all patients, fell upon cotton pants which produced an exothermic reaction due to the cellulose and extensive hydroxyl groups in the cotton [70]. Knowing that contact with the skin at temperatures greater than $40{ }^{\circ} \mathrm{C}$ causes damage, Keleman et al. analyzed the peak temperatures reached by four types of nail glues. All reached temperatures above $60{ }^{\circ} \mathrm{C}$, with one reaching a temperature of $75^{\circ} \mathrm{C}$ [70]. Therefore, there is serious potential for harm through flammability of acrylic nails and nail glue.

Secondary adverse effects of artificial nails have been noted. For instance, studies have been conducted to determine whether the use of artificial nails increases the risk of bacterial transfer. Comparisons have been done between artificial nails and natural nails after handwashing, concluding that artificial nails carried more gram-negative bacilli, staphylococcus aureus, enterococci, and yeast [71-74]. This suggests that artificial nails could be a nidus for nosocomial infections in health care facilities, and that the longer they are worn, the more pathogens they accumulate [71]. There have also been studies analyzing the effect of artificial nails on pulse oximetry readings, although results have been conflicting. A study by Hinkelbein et al. [75] compared oxygen saturations on natural nails versus acrylic nails in both standard and sideways positions. It was found that with acrylic nails, there was a greater difference between the standard and sideways readings than with natural nails, suggesting a possible interference due to the artificial nails [75]. On the contrary, three other studies concluded that oxygen saturation values obtained from fingers with natural nails versus acrylic nails were not statistically significantly different and it was unnecessary to remove acrylic nails for the purpose of pulse oximetry monitoring [26,76,77]. In addition, artificial nails have been shown to mask nail bed injury, such as subungual hematomas, in traumatic injuries of the distal phalanx. Proper removal of the nail with a solvent and analysis of the underlying digit therefore becomes necessary [78].

As for a secondary positive effect of artificial nails, they have been used to treat ingrown nails and nail bed hypoplasia following the traumatic loss of the body of the nail [79]. The application of the acrylic nail places pressure on the distal nail bed and hyponychium, which helps resolve distal ingrowing of the nail. They have also been used as a splint in the treatment of nail lacerations associated with distal phalangeal trauma and fractures [80]. One study even evaluated UV-cured gel nails as medium to deliver topical antifungals directly to the nail. This would allow the nail to be exposed to the medicine for a longer period of time, increasing compliance and success with treatment [81]. 


\subsubsection{Discussion}

A majority of the safety concerns related to artificial nails are due to ACD through sensitization to aspects of the nails, particularly methacrylate monomers. Some reactions to ethyl cyanoacrylate in the glue component have been reported, but a majority of cases report reactions to methacrylates such as MMA, 2-HEMA, and EGDMA. The use of pure methyl methacrylate compounds has been largely discontinued due to legislation restricting its usage [35]. Regardless, MMA has been sampled in the ambient air of nail salons, which suggests that its usage continues [82]. In addition, the use of other methacrylate monomers is still allowed. Cosmetic Ingredient Review Expert panel (CIR) reports that methacrylate monomers such as ethyl acrylate can be sensitizers but not potent ones and their use should be restricted to professionals, with avoidance of skin contact to prevent sensitization and future cross-reactivity [33]. However, their assessments are based largely on animal studies as opposed to human trials, due to the lack of clinical studies and randomized trials done on the topic. A majority of the clinical data available is through case reports, which do not provide substantial evidence. Furthermore, it is understood that the sensitizing ability of the monomers occurs when they are not completely polymerized [7]. However, whether methacrylate sensitization can be achieved through application on the nail in addition to skin contact is not a concept that is discussed in a majority of available case reports. Due to the many case reports of reactivity and cross-reactivity with other methacrylate monomers, further evaluation of the safety and usage of acrylates in nail products by governments is warranted. Additional retrospective studies and randomized controlled trials regarding methacrylate sensitivity and its long-term effects would also be useful in understanding the safety of artificial nails.

Methacrylates also have a high degree of cross-reactivity, meaning that once one is sensitized to one type of monomer, they are more likely to react to other methacrylate monomers as well, despite having no direct contact with them. Therefore, patients who are sensitized to methacrylates must be careful about avoidance, especially if their profession involves contact with methacrylate products, such as in dentistry or printing [49]. Direct skin contact should be avoided and the appropriate gloves should be used when handling compounds which may potentially cause an adverse reaction. Methacrylate cross-reactivity with cyanoacrylates has not been well-established [83].

In the light of the extensive contact allergies associated with particular methacrylate monomers, several authors have suggested different combinations of monomers for patch testing in order to screen for possible methacrylate allergy. Scheers et al. suggested that 2-HEMA, TREGDA, and EGDMA were good screening monomers [56], while Koppula et al. suggested a combination of EA, 2-HEMA, EGDMA, TREGDA, and ethyl cyanoacrylate to screen [84]. While some authors consider testing two monomers such as 2-HEMA and TREGDA as enough [44], others consider that a screen of 10 acrylics might be necessary, especially for patients who have reactions and want to continue the use of nail cosmetics [34]. Although many different combinations have been suggested, the common denominators tend to be 2-HEMA, EGDMA, and TREGDA. 2-HPMA has also been found to be commonly positive on patch tests and could be considered in screening. Initial screening may even be done with one or two compounds, particularly 2-HEMA [85], and additional monomers may be added if there is strong suspicion of acrylate allergy [44].

Additional concerns with regards to artificial nails include their potential to harbor pathogens [71], which may make them a poor choice for nail beautification in health care settings, and their potential flammability $[69,70]$. Artificial nails and nail glue should not be brought near flames and caution is advised when applying the nails since contact of nail glue with cotton or denim may lead to skin burns. Furthermore, application of the artificial nails themselves can lead to wearing down of the fingernails so if the nails appear thin, coarse, and dull, gaps between application of artificial nails is advised [68]. Occupational exposure to methacrylates and other harmful compounds may lead to adverse health effects discussed in a later section. 


\subsection{Nail Polish and Nail GlueRremover}

\subsubsection{Introduction}

Nail polish remover is often an organic solvent with added scents and colors. The classic and most recognized remover is acetone. More recently, acetone-free liquids have been commercialized which largely consist of gamma-butyrolactone (GBL) [86]. Ethyl acetate may be another organic solvent used for removal of nail polish [87]. Nail polish removers may come in different presentations: from a bottled liquid requiring cotton balls or pads for application, to pre-submerged pads, to liquid infused into a foam in which one inserts their finger to clean their nail.

\subsubsection{Findings}

The major health risk associated with nail polish and nail glue removers seems to be due to ingestion of the substances. Ingestion of acetone may cause lethargy, confusion, and decreased arousability for several hours [88]; serious health effects and death are unlikely due to acetone. Similar but more serious toxicity due to acetone-free nail polish remover has been reported. Brown reported a case of a 15-month-old who ingested "acetone-free" nail polish remover, leading to cardiorespiratory collapse and coma [89]. A similar event was noted in a 9-month-old child who consumed "acetone-free" nail polish remover and presented with vomiting, hypotension, bradycardia, respiratory acidosis, and a Glasgow Coma Score of three. The patient the proceeded to become giddy and hyperalert, and eventually fully recovered in eight hours [86]. The major chemical in acetone-free nail polish remover is gamma-butyrolactone which is converted to gamma-hydroxybutyrate (GHB), a compound with recognized toxic effects when ingested $[86,90]$. Although these cases improved with time and supportive care, careful observation was necessary to ensure recovery.

Episodes of vomiting, cyanosis, lethargy, low $\mathrm{SpO}_{2}$ (blood oxygen saturation), increased $\mathrm{pO}_{2}$ (partial pressure of oxygen), and altered mental status have occurred due to substances such as $N, N$-dimethyl- $p$-toluidine and nitroethane, which are present as solvents in some nail polish removers [91-95]. Both these substances give rise to methemoglobinemia, which can be potentially deadly if not treated with IV fluids, oxygen, and methylene blue. Ingestion of $N, N$-dimethyl- $p$-toluidine or nitroethane-based nail polish remover and the development of cyanosis and methemoglobinemia have been reported in adults as well as children [91-95].

Several cases of ingestion of nail glue and artificial nail removers have been reported as well. Several authors have reported cases of infants consuming small amounts of artificial nail remover and subsequently developing cyanosis and methemoglobinemia [91,96]. In these cases, the main compound consumed in the nail remover was nitroethane, and both patients improved with methylene blue treatment.

Acetonitrile has also been identified as a toxic compound in artificial nail remover. Many cases have described cyanide poisoning with altered mental status, cardiorespiratory instability, vomiting, severe metabolic acidosis, and generalized seizure in patients, resolving only with sodium thiosulfate [97-99]. In one case, a 16-month-old child consumed acetonitrile-containing nail glue remover, which was confused for acetone-containing nail polish remover by the poison control telephone operators. Expecting recovery with time, the child was put to bed only to be found dead the next morning due to cyanide poisoning [97]. This case demonstrated that acetone and acetronitrile can be easily confused, and the importance of distinguishing the causative agent and treating appropriately. Although most cases are described as accidental ingestions in the pediatric population, adult consumption as attempted suicide has also been reported [100]. One case of ingestion in adult patient exhibited complication in treatment. Although the patient responded to sodium thiosulfate and sodium nitrite, the patient's condition relapsed several times, needing several doses of sodium thiosulfate and hemodialysis/hemoperfusion to correct the resulting hypernatremia [100]. Evidently, consumption of artificial nail remover can lead to serious medical morbidity, with days of hospitalization and possibly death if left untreated. 
Allergy to nail polish remover is not well documented. However, a case of two women with eczematous reactions and history of nail polish and nail polish remover use was reported. The women tested positive for allergy against benzophenone-2, a compound used in nail polish remover, as well as TSFR in nail polish. The women's symptoms improved after discontinuation of both nail polish and nail polish remover [18]. In addition, proper removal of gel nails, which are often strongly adhered to the nail plate, requires soaking the nails in acetone or other solvents for 10-15 minutes. This prolonged exposure to acetone has been associated with onychoschizia (splitting of the nail), pseudo-leukonychia (white discoloration of the nail), and overall thinning and brittleness of the fingernails [10].

\subsubsection{Discussion}

The local use of nail glue and polish removers seems to be without significant adverse effects. Ingestion of these removers is the primary cause of concern. Accidental ingestion has been largely documented among the pediatric population, however some cases of intentional ingestion with suicidal intent have also been documented among adults. Consumption of chemicals such as acetone and GBL may lead to a worrisome clinical presentation initially, with vomiting, coma, and cardiorespiratory demise $[86,90]$. These cases, however, usually respond well to supportive treatment and improve clinically with time. In the United States, GBL's use has now been restricted due its metabolization into GHB, a common date-rape drug used for intoxication [101].

Acetonitrile has been used in some nail polish removers and is more prevalent in artificial nail removers. Although acetonitrile itself has minimal toxicity consisting of irritation to the skin, eyes, and oropharynx, the compound is metabolized to thiocyanate and hydrogen cyanide with time, which is main cause of its morbidity and mortality [102]. The symptoms usually have an onset 3 to $12 \mathrm{~h}$ after ingestion [97] and include acidosis, cardiorespiratory instability, and seizures, as described above. The United States now requires child-resistant packaging for all glue removers with greater than $500 \mathrm{mg}$ of acetonitrile, while the compound has been banned in the European Economic area since 2000 due to its carcinogenic and toxic potential. Nitroethane is another compound used in nail polish removers which may be toxic through metabolism into nitrites and nitrates, and production of methemoglobinemia [103]. Similarly to acetonitrile, nitroethane may cause delayed-onset and recurrent cyanosis, in need of close observation and treatment [92].

Again, not much evidence linking nail polish or glue removers to dermatitis or allergies were found. The one report which did present a female with allergy to benzophenone-2, a compound sometimes found in nail polish remover, also presented confounding allergies to substances found in nail polish and artificial nails [18]. In addition, no studies could be found about the efficacy of nail polish or glue removers, or about which compounds are more efficient or beneficial. More research and understanding relating to these removers are necessary. Further understanding of the toxicity, long-term effects, and toxic concentrations of compounds in these removers is also necessary and would aid in guiding legislation regarding their use. Furthermore, for products containing chemicals with potentially lethal health effects such as acetonitrile, the use of visible warnings on the product in addition to having child-resistant containers might prove helpful. If ingestion does occur, consumption of acetone should be distinguished from that of acetonitrile. While acetone poisoning will likely resolve with time, untreated acetonitrile may lead to death; misdiagnosis of acetonitrile poisoning for acetone poisoning may be life threatening.

\subsection{Other Nail Products}

Adverse effects with other nail cosmetics have been reported as well. Accidental ingestion of nail primer has been recorded in children, leading to corrosive effects on the skin as well as extensive burning and ulceration throughout the gastrointestinal tract [104]. Nail primers contain high concentrations of methacrylic acid, which can react with liquid and cause burning of the skin, eyes, and mucous membranes. A retrospective study analyzed emergency department visits and poison control center calls for children less than 6 years old who were exposed to nail primers containing methacrylic 
acid. The study found 769 nail product exposures, out of which 32 were due to nail primers [105]. These exposures included ingestion, ocular exposure, and mostly dermal exposures, all corrosive in nature. Most of the associated injuries were dermal burns and 20 out of the 32 injuries were rated as moderate-to-severe injuries, but no deaths were associated [105].

Nail hardeners have been linked to ACD, often due to reactions to chemicals similar to those found in nail varnish. For instance, a 59-year-old female developed pain and subungual hemorrhage, followed by onycholysis (separation of nail from nail bed) and nail plate shedding after three weeks of using a nail hardener with $2.8 \%$ formaldehyde. Nail cultures came back negative for fungus and patch test demonstrated a strong reaction to formaldehyde and quaternium [106]. Eczematous reactions to TSFR in nail hardeners have also been documented [16,17,107], sometimes mimicking onychomycosis [15]. de Wit et al. [107] found that women who had applied nail lacquer for several years without developing an adverse reaction developed dermatitis with the use of nail hardeners. They speculated that since nail hardeners contain more free formaldehyde than nail polish, increased concentrations of free formaldehyde might increase the risk of sensitization to TSFR in nail hardeners [107]. Pterygium inversum unguis has also been associated with nail hardeners and other formaldehyde-containing compounds such as acrylics and gel nail polish. Although the causal relationship between these nail products and pterygium inversum is not clearly understood, overgrowth of the distal nail bed with adherence to the ventral nail plate has been observed. Due to the stretching of the neurovascular bundle in the hyponychium, this may be very painful and require systemic corticosteroids for relief [108].

Finally contact allergy has also been associated with nail wrapping. Nail wraps are a material, often silk or linen, laid down upon the natural nail plate in order to strengthen it [34]. Once the wrap is laid down, nail polish is applied above it to conceal the wrap and to allow for beautification of the nail. The cases of three females who developed pruritic rash of the hands as well as periungual dermatitis and paronychia were reported. One woman also developed a pruritic rash on the eyelids as well as a nummular dermatitis along her dorsal hands [109]. Ethyl cyanoacrylate was found to be allergen in these cases.

\subsection{Occupational Exposure}

Studies have been done analyzing nail salons and the occupational health risks associated with them. Several cases of occupational ACD have been discussed above. Sensitization to compounds such as methacrylates is theorized to happen through accidental skin contact [110], however long term ambient exposure and hand-transfer may also contribute to the development and the distribution of ACD in nail technicians. In a study of 14 patients with ACD to methacrylate monomers in acrylic nails, it was found that nail technicians had a greater proportion of positive patch test reactions than customers, suggesting that nail technicians might be more susceptible to sensitization [111]. Many studies focused on the concentration of volatile organic compounds and harmful chemicals such as formaldehyde and methacrylates in the air of nail salons. For instance, 12 randomly-selected nail salons in Salt Lake City, Utah, US were analyzed for the concentration of volatile organic compounds in the facilities. Although methyl methacrylate compounds are reportedly banned in nail products in Utah, $58 \%$ of facilities had detectable levels in the air [112]. 58\% of establishments also had detectable formaldehyde above the recommended exposure limits set by the National Institute for Occupational Safety and Health in the US (> 0.016 parts per million (ppm)) [112]. A study of air in Californian salons revealed that measured values of isopropyl alcohol and ethyl acetate were within the California Division of Occupational Safety and Health's occupational limits. However, the average measured value of toluene from personal air monitoring was greater than the $0.08 \mathrm{ppm}$, which is recommended by the California Environmental Protection Agency [82]. Although MMA is banned, the average level of MMA was measured at $0.54 \mathrm{ppm}$, which is several times higher than the recommended $0.17 \mathrm{ppm}$. The concentration of total volatile organic compounds were also well over the recommended values for indoor nonindustrial workers. The workers who were studied reported systemic symptoms including: nausea, headaches, and irritation of the eyes, nose, throat, skin, and respiratory tract [82]. These 
symptoms are likely the result of spending long hours with high concentrations of irritating chemicals in the ambient air. Eye, nose, and throat irritation have been common complaints among nail salon workers in other studies as well [113,114].

Neurocognitive and neurosensory deficits have also been studied in nail salon workers. One study showed that nail technicians had decreased olfaction and performed more poorly on tasks that required processing speed and attention than controls [115]. Nail technicians also reported increased self-reported symptoms of decreased memory, learning, and cognition [116]. Long-term exposure to substances such as methacrylates which have known neurotoxicity may cause neurologic deficits in nail salon workers.

As can be seen, nail salon workers are at an increased risk for many harmful exposures. Steps have been taken to try to better the working conditions of these workers and to decrease their exposure. For instance, the city of San Francisco, California passed the San Francisco Nail Salon Recognition Ordinance in 2010 in an effort to protect nail salon workers with a safer working environment [117]. The program intended to increase safety by instating the following: use of nail polishes without dibutyl phthalate, toluene, and formaldehyde, use of safer nail polish removers, the use of nitrile gloves by workers, appropriate ventilation of the salon with mechanical ventilation being preferred, training of all the workers, monitoring of the air quality by local authorities, etc [117]. With the program, toluene and total volatile concentrations in the air decreased, although the difference was not statistically significant. MMA concentrations were actually increased, however. The program also increased the workers' awareness of dibutyl phthalates in nail products [117]. Results of the program, although a step in the right direction, were not as intended. The aerosolized concentration of many harmful compounds remained statistically similar to before or increased. Also, the impact of the program on the health of the workers was not evaluated. An increase in such programs allowing for regulation of nail salons and monitoring for air quality is needed. Additional literature regarding the long-term adverse effects on workers with and without such regulatory programs is also needed in order to determine their efficacy.

Increasing the safety of nail salons should be a continual effort. As reported above, salons accumulate high levels of harmful compounds, some of which are restricted for use in nail cosmetics. Clearly, better ventilation and more regular analysis of the air content of salons are needed. Ingredients of nail products should also be more carefully checked to decrease exposure to toxins and allergens, especially those which are banned. Finally, the proper use of masks and gloves by nail technicians should be emphasized. Rubber gloves may be permeated by acrylates so gloves composed of nitrile or neoprene should be used to prevent skin contact and sensitization to allergens [118]. For technicians who have previous exposure and ACD to chemicals such as methacrylates, the use of gloves to prevent recurrence becomes even more important.

\section{Conclusions}

The beautification of fingernails through nail cosmetics is a widely accepted practice, but there is not enough concrete knowledge about nail products and the chemicals within them. Several caes and studies have confirmed adverse effects due to nail products, summariezed in Table 1. Nail polish and artificial nails are among the most common nail products used, and the major safety concern associated with them remains allergic contact dermatitis due to sensitizers such as TSFR and methacrylates. Furthermore, chemical and mechanical damage to the nail as a result of extended artificial nail use has been documented. There is also concern for accidental or intentional ingestion of products such as nail primers, nail polish removers, and nail glue removers, all which may cause severe morbidity and possible mortality if consumed. Occupational hazards associated with nail products are not limited to ACD. Due to aerosolization of compounds, health effects such as eye and throat irritation, asthma, and even neurocognitive changes may be observed. Methacrylates not only have the ability to cause allergic and irritant contact dermatitis, but also have several systemic effects such as respiratory irritation, neuropathy, altered mental status, gastrointestinal irritation, and fetotoxicity [119]. Compounds 
such as formaldehyde and toluene are not only irritating to mucous membranes and potentially carcinogenic, but also they may have negative effects on the nervous system, the cardiovascular system, the gastrointestinal system, the renal system, etc. [120]. The morbidity associated with occupational $A C D$ and respiratory irritation can be very debilitating, and can even cause workers to take leave or retire from their occupation $[24,60]$.

The pool of knowledge regarding the safety of nail products remains largely case reports. Therefore, more long term retrospective studies and randomized controlled trials are needed to determine the safety of these compounds and that of the chemicals within them. Although there are efforts in place by government agencies to increase the safety of cosmetics, legislation will be inadequate until more hard evidence about the safety of nail cosmetics is garnered. The efficacy of nail cosmetics has not been studied well at all and should be a topic for future research.

Table 1. Adverse Effects Associated with Nail Cosmetic Products.

\begin{tabular}{cl}
\hline Cosmetic Product & \multicolumn{1}{c}{ Adverse Effect } \\
\hline Nail Polish & $\begin{array}{l}\text { Superficial nail discoloration, pseudo-leukonychia, allergic contact } \\
\text { dermatitis (local and distal), microbial colonization, distorted pulse } \\
\text { oximetry readings } \\
\text { Allergic contact dermatitis (local and distal), methacrylate sensitization } \\
\text { and cross-reactivity, rhinitis/wheezing, nail brittleness and thinning, } \\
\text { flammability, microbial colonization, mask nail bed injury }\end{array}$ \\
& $\begin{array}{l}\text { Allergic contact dermatitis (local and distal), methacrylate sensitization } \\
\text { and cross-reactivity, rhinitis/wheezing, nail brittleness and thinning; } \\
\text { malignant potential with UV exposure }\end{array}$ \\
Photobonded Nails & Altered mental status, cardiopulmonary decline, and nausea/vomiting \\
& with ingestion; potential for methemoglobinemia, coma, and death with \\
& ingestion; nail brittleness and thinning \\
Nail Polish / Nail Glue Remover & Corrosive to mucus membranes, dermal burns \\
& Allergic contact dermatitis \\
Nail Primers & Allergic contact dermatitis \\
Nail Hardener & Nail Wraps
\end{tabular}

Author Contributions: Both authors contributed to writing this paper.

Conflicts of Interest: The authors declare no conflict of interest.

\section{References}

1. Regulations Related to Cosmetics. Secondary Regulations Related to Cosmetics. Available online: https:/ / www.fda.gov/Cosmetics/GuidanceRegulation/LawsRegulations/ucm126613.htm (accessed on 1 June 2017).

2. Alani, J.I.; Davis, M.D.; Yiannias, J.A. Allergy to cosmetics: A literature review. Dermatitis 2013, 24, $283-290$. [CrossRef] [PubMed]

3. SUE Reporting Guidlines. Available online: http:/ /ec.europa.eu/consumers/sectors/cosmetics/files/pdf/ sue_reporting_guidelines_en.pdf (accessed on 1 June 2017).

4. Voluntary Cosmetic Registration Program. Secondary Voluntary Cosmetic Registration Program 2017. Available online: http://www.fda.gov/Cosmetics/RegistrationProgram/ucm2005171.htm (accessed on 1 June 2017).

5. Bruze, M.; Uter, W.; Goncalo, M.; Lepoittevan, J.P.; Diepgen, T.; Orton, D. Incompetence and failure to regulate methylisothiazolinone. Contact Dermat. 2015, 72, 353-354.

6. Regulation (EC) No 1223/2009 of the European Parliament and of the Council. Available online: http:/ / ec.europa.eu/health//sites/health/files/endocrine_disruptors/docs/cosmetic_1223_2009_ regulation_en.pdf (accessed on 9 July 2017).

7. Moossavi, M.; Scher, R.K. Nail care products. Clin. Dermatol. 2001, 19, 445-448. [CrossRef]

8. Draelos, Z.D. Cosmetic treatment of nails. Clin. Dermatol. 2013, 31, 573-577. [CrossRef] [PubMed]

9. Baran, R. Nail cosmetics: Allergies and irritations. Am. J. Clin. Dermatol. 2002, 3, 547-555. [CrossRef] 
10. Rieder, E.A.; Tosti, A. Cosmetically induced disorders of the nail with update on contemporary nail manicures. J. Clin. Aesthet. Dermatol. 2016, 9, 39-44.

11. Mlacker, S. White superficial onychomycosis. In Onychomycosis: An Illustrated Guide to Diagnosis and Treatment; Tosti, A., Vlahovic, T., Arenas, R., Eds.; Springer: New York, NY, USA, 2017; pp. 35-44.

12. Castelain, M.; Veyrat, S.; Laine, G.; Montastier, C. Contact dermatitis from nitrocellulose in a nail varnish. Contact Dermat. 1997, 36, 266-267. [CrossRef] [PubMed]

13. Fiume, M.M.; Bergfeld, W.F.; Belsito, D.V.; Hill, R.A.; Klaassen, C.D.; Liebler, D.C.; Marks, J.G.; Shank, R.C.; Slaga, T.J.; Snyder, P.W.; et al. Safety assessment of nitrocellulose and collodion as used in cosmetics. Int. J. Toxicol. 2016, 35, 50S-59S. [CrossRef] [PubMed]

14. Fuchs, T.; Gutgesell, C. Is contact allergy to toluene sulphonamide-formaldehyde resin common? Br. J. Dermatol. 1996, 135, 1013-1014. [CrossRef] [PubMed]

15. Paltzik, R.L.; Enscoe, I. Onycholysis secondary to toluene sulfonamide formaldehyde resin used in a nail hardener mimicking onychomycosis. Cutis 1980, 25, 647-648. [PubMed]

16. De Groot, A.C. Contact allergy to cosmetics: causative ingredients. Contact Dermat. 1987, 17, $26-34$. [CrossRef] [PubMed]

17. De Groot, A.C.; Bruynzeel, D.P.; Bos, J.D.; van der Meeren, H.L.; van Joost, T.; Jagtman, B.A.; Weyland, J.W. The allergens in cosmetics. Arch. Dermatol. 1988, 124, 1525-1529. [CrossRef] [PubMed]

18. Boehncke, W.H.; Schmitt, M.; Zollner, T.M.; Hensel, O. Nail polish allergy. An important differential diagnosis in contact dermatitis. Dtsch. Med. Wochenschr. 1997, 122, 849-852. [CrossRef] [PubMed]

19. Giorgini, S.; Brusi, C.; Francalanci, S.; Gola, M.; Sertoli, A. Prevention of allergic contact dermatitis from nail varnishes and hardeners. Contact Dermat. 1994, 31, 325-326. [CrossRef] [PubMed]

20. Jacob, S.E.; Stechschulte, S.A. Tosylamide/formaldehyde resin allergy- - - A consideration in the atopic toddler. Contact Dermat. 2008, 58, 312-313. [CrossRef] [PubMed]

21. Ockenfels, H.M.; Seemann, U.; Goos, M. Contact allergy in patients with periorbital eczema: An analysis of allergens. Data recorded by the Information Network of the Departments of Dermatology. Dermatology 1997, 195, 119-124. [CrossRef] [PubMed]

22. Hines, E.P.; Calafat, A.M.; Silva, M.J.; Mendola, P.; Fenton, S.E. Concentrations of phthalate metabolites in milk, urine, saliva, and Serum of lactating North Carolina women. Environ. Health Perspect. 2009, 117, 86-92. [CrossRef] [PubMed]

23. Sipahi, H.; Charehsaz, M.; Gungor, Z.; Erdem, O.; Soykut, B.; Akay, C.; Aydin, A. Risk assessment of allergen metals in cosmetic products. J. Cosmet. Sci. 2015, 66, 313-323. [PubMed]

24. Liden, C.; Berg, M.; Farm, G.; Wrangsjö, K. Nail varnish allergy with far-reaching consequences. Br. J. Dermatol. 1993, 128, 57-62. [CrossRef]

25. Wynd, C.A.; Samstag, D.E.; Lapp, A.M. Bacterial carriage on the fingernails of OR nurses. AORN J. 1994, 60, 99-805. [CrossRef]

26. Desalu, I.; Diakparomre, O.I.; Salami, A.O.; Abiola, A.O. The effect of nail polish and acrylic nails on pulse oximetry reading using the Lifebox oximeter in Nigeria. Niger. Postgrad. Med. J. 2013, 20, 331-335. [PubMed]

27. Couteau, C.; Paparis, E.; Coiffard, L. Comparison of different nail polish in terms of photoprotective efficacy. Interest of their use as supportive care in patients with cancer. Bull. Cancer 2016, 103, 612-621. [CrossRef] [PubMed]

28. US Food and Drug Administration. Formaldehyde in Nail Hardeners and Nail Polishes; FDA: Silver Spring, MD, USA, 2016.

29. Scientific Committee on Consumer Safety; Bernauer, U.; Coenraads, P.J.; Degen, G.H.; Dusinska, M.; Lilienblum, W.; Luch, A.; Nielsen, E.; Platzek, T.; Rastogi, S.; et al. Opinion of the Scientific Committee on Consumer Safety (SCCS)—The safety of the use of formaldehyde in nail hardeners. Regul. Toxicol. Pharmacol. 2015, 72, 658-659. [CrossRef] [PubMed]

30. Guin, J.D.; Baas, K.; Nelson-Adesokan, P. Contact sensitization to cyanoacrylate adhesive as a cause of severe onychodystrophy. Int. J. Dermatol. 1998, 37, 31-36. [CrossRef] [PubMed]

31. Yokota, M.; Thong, H.Y.; Hoffman, C.A.; Maibach, H.I. Allergic contact dermatitis caused by tosylamide formaldehyde resin in nail varnish: an old allergen that has not disappeared. Contact Dermat. 2007, 57, 277. [CrossRef] [PubMed]

32. Commission, E. Specific Products, Standards and Risks. Available online: http:/ /ec.europa.eu/consumers / consumers_safety/product_safety_legislation/standards/index_en.htm (accessed on 13 July 2017). 
33. Cosmetic Ingredient Review (CIR) program Expert Panel. Annual Review of Cosmetic Ingredient Safety Assessments-2002/2003. Int. J. Toxicol. 2005, 24 (Suppl 1), 1-102.

34. Constandt, L.; Hecke, E.V.; Naeyaert, J.M.; Goossens, A. Screening for contact allergy to artificial nails. Contact Dermat. 2005, 52, 73-77. [CrossRef] [PubMed]

35. US Food and Drug Administration. Methacrylate Monomers in Artificial Nails ("Acrylics"); FDA: Silver Spring, MD, USA, 2016.

36. SGS (Société Générale de Surveillance). Insight into Cosmetics Recalls Since EU Cosmetic Regulation Implementation; SGS: Geneva, Switzerland, 2014.

37. Scientific Review of Ultraviolet (UV) Radiation, Broad Spectrum and UVA, UVB, and UVC; 14th Report on Carcinogens; U.S. Department of Health and Human Services: Washington, DC, USA, 2014.

38. Professional Beauty Association (PBA). Understanding UV Nail Lamps. Available online: https:// www.schoonscientific.com/downloads/tech-articles/Understanding-UV-Nail-Lamps.pdf (accessed on 13 July 2017).

39. Nanda, S.; Grover, C. Utility of gel nails in improving the appearance of cosmetically disfigured nails: Experience with 25 cases. J. Cutaneous Aesthet. Surg. 2014, 7, 26-31.

40. Canizares, O. Contact dermatitis due to the acrylic materials used in artificial nails. Arch. Dermatol. 1956, 74, 141-143. [CrossRef]

41. Fisher, A.A.; Franks, A.; Glick, H. Allergic sensitization of the skin and nails to acrylic plastic nails. J. Allergy 1957, 28, 84-88. [CrossRef]

42. Fisher, A.A. Permanent loss of finger nails from sensitization and reaction to acrylic in a preparation designed to make artificial nails. J. Dermatol. Surg. Oncol. 1980, 6, 70-71. [CrossRef]

43. Le, Q.; Cahill, J.; Palmer-Le, A.; Nixon, R. The rising trend in allergic contact dermatitis to acrylic nail products. Australas. J. Dermatol. 2015, 56, 221-223. [CrossRef] [PubMed]

44. Cravo, M.; Cardoso, J.C.; Goncalo, M.; Figueiredo, A. Allergic contact dermatitis from photobonded acrylic gel nails: a review of four cases. Contact Dermat. 2008, 59, 250-251. [CrossRef] [PubMed]

45. Hemmer, W.; Focke, M.; Wantke, F.; Götz, M.; Jarisch, R. Allergic contact dermatitis to artificial fingernails prepared from UV light-cured acrylates. J. Am. Acad. Dermatol. 1996, 35, 377-380. [CrossRef]

46. Alcantara-Nicolas, F.A.; Pastor-Nieto, M.A.; Sanchez-Herreros, C.; Pérez-Mesonero, R.; Melgar-Molero, V.; Ballano, A.; De-Eusebio, E. Allergic contact dermatitis from acrylic nails in a flamenco guitarist. Occup. Med. 2016, 66, 751-753. [CrossRef] [PubMed]

47. Machado, P.; Pereira, D.; Morais, P. An itchy rash on the fingertips-A case study. Aust. Fam. Physician 2014, 43, 36-37. [PubMed]

48. Maio, P.; Carvalho, R.; Amaro, C.; Santos, R.; Cardoso, J. Allergic contact dermatitis from sculptured acrylic nails: Special presentation with an airborne pattern. Dermatol. Rep. 2012, 4, e6. [CrossRef] [PubMed]

49. Leggat, P.A.; Smith, D.R.; Kedjarune, U. Surgical applications of methyl methacrylate: A review of toxicity. Arch. Environ. Occup. Health 2009, 64, 207-212. [CrossRef] [PubMed]

50. Roche, E.; de la Cuadra, J.; Alegre, V. Sensitization to acrylates caused by artificial acrylic nails: Review of 15 cases. Actas Dermo-Sifiliogr. 2008, 99, 788-794. [CrossRef]

51. Sood, A.; Taylor, J.S. Acrylic reactions: a review of 56 cases. Contact Dermat. 2003, 48, 346-347. [CrossRef] [PubMed]

52. Lazarov, A. Sensitization to acrylates is a common adverse reaction to artificial fingernails. J. Eur. Acad. Dermatol. Venereol. 2007, 21, 169-174. [CrossRef] [PubMed]

53. Mattos, S.; Mendonca, M.; LaSenna, C.; Tosti, A. Severe onychodystrophy due to allergic contact dermatitis from acrylic nails. Skin Appendage Disord. 2015, 1, 91-94. [CrossRef] [PubMed]

54. Freeman, S.; Lee, M.S.; Gudmundsen, K. Adverse contact reactions to sculptured acrylic nails: 4 case reports and a literature review. Contact Dermat. 1995, 33, 381-385. [CrossRef] [PubMed]

55. Guin, J.D. Eyelid dermatitis from methacrylates used for nail enhancement. Contact Dermat. 1998, 39, 312-313. [CrossRef] [PubMed]

56. Scheers, C.; Andre, J.; Negulescu, M.; Blondeel, A.; Kolivras, A. Recurrent cheilitis and lip oedema caused by (meth)acrylates present in ultraviolet-curable nail lacquer. Contact Dermat. 2015, 72, 341-342. [CrossRef] [PubMed] 
57. Rajan, S.O.D.; Chowdhury, M.M.; Wilkinson, S.M.; Reckling, C.; Shah, A.; Johnston, G.A.; Bourke, J.F.; Green, C.; Ghaffar, S.A.; Buckley, D. Contact allergy to (meth)acrylates: A U.K. multicentre study. Contact Dermat. 2016, 75, 41-42.

58. Uter, W.; Geier, J. Contact allergy to acrylates and methacrylates in consumers and nail artists - data of the Information Network of Departments of Dermatology, 2004-2013. Contact Dermat. 2015, 72, 224-228. [CrossRef] [PubMed]

59. DeKoven, S.; DeKoven, J.; Holness, D.L. (Meth)Acrylate Occupational Contact Dermatitis in Nail Salon Workers. J. Cutaneous Med. Surg. 2017, 21, 340-344. [CrossRef] [PubMed]

60. Sauni, R.; Kauppi, P.; Alanko, K.; Henriks-Eckerman, M.L.; Tuppurainen, M.; Hannu, T. Occupational asthma caused by sculptured nails containing methacrylates. Am. J. Ind. Med. 2008, 51, 968-974. [CrossRef] [PubMed]

61. Macedo, N.A.; Carmona, C.; Pineyro, I. Contact dermatitis from acrylic nails. Contact Dermat. 1995, 32, 362. [CrossRef] [PubMed]

62. Giroux, L.; Pratt, M.D. Contact dermatitis to incontinency pads in a (meth)acrylate allergic patient. Am. J. Contact Dermat. 2002, 13, 143-145. [CrossRef] [PubMed]

63. MacFarlane, D.F.; Alonso, C.A. Occurrence of nonmelanoma skin cancers on the hands after UV nail light exposure. Arch. Dermatol. 2009, 145, 447-449. [CrossRef] [PubMed]

64. Markova, A.; Weinstock, M.A. Risk of skin cancer associated with the use of UV nail lamp. J. Investig. Dermatol. 2013, 133, 1097-1099. [CrossRef] [PubMed]

65. Shipp, L.R.; Warner, C.A.; Rueggeberg, F.A.; Davis, L.S. Further investigation into the risk of skin cancer associated with the use of UV nail lamps. JAMA Dermatol. 2014, 150, 775-776. [CrossRef] [PubMed]

66. Curtis, J.; Tanner, P.; Judd, C.; Childs, B.; Hull, C.; Leachman, S. Acrylic nail curing UV lamps: High-intensity exposure warrants further research of skin cancer risk. J. Am. Acad. Dermatol. 2013, 69, 1069-1070. [CrossRef] [PubMed]

67. Wu, T.P.; Morrison, B.W.; Tosti, A. Worn down nails after acrylic nail removal. Dermatol. Online J. 2015, $21,14$.

68. Pinteala, T.; Chiriac, A.E.; Rosca, I.; Filon, F.L.; Pinteala, M.; Chiriac, A.; Podoleanu, C.; Stolnicu, S.; Coros, M.F.; Coroaba, A. Nail Damage (Severe Onychodystrophy) Induced by Acrylate Glue: Scanning Electron Microscopy and Energy Dispersive X-Ray Investigations. Skin Appendage Disord. 2017, 2, 137-142. [CrossRef] [PubMed]

69. Arnaout, A.; Cubitt, J.; Nguyen, D. Beware flammable fingernails. Case report: synthetic fingernails result in full thickness burn and terminalisation. Ann. Burns Fire Disasters 2016, 29, 144-145. [PubMed]

70. Kelemen, N.; Karagergou, E.; Jones, S.L.; Morritt, A.N. Full thickness burns caused by cyanoacrylate nail glue: A case series. Burns 2016, 42, e51-e54. [CrossRef] [PubMed]

71. Hedderwick, S.A.; McNeil, S.A.; Lyons, M.J.; Kauffman, C.A. Pathogenic organisms associated with artificial fingernails worn by healthcare workers. Infect. Control Hosp. Epidemiol. 2000, 21, 505-509. [CrossRef] [PubMed]

72. Mathias, J.M. Acrylic nails harbor pathogens. OR Manag. 2000, 16, 10.

73. McNeil, S.A.; Foster, C.L.; Hedderwick, S.A.; Kauffman, C.A. Effect of hand cleansing with antimicrobial soap or alcohol-based gel on microbial colonization of artificial fingernails worn by health care workers. Clin. Infect. Dis. 2001, 32, 367-372. [CrossRef] [PubMed]

74. Pottinger, J.; Burns, S.; Manske, C. Bacterial carriage by artificial versus natural nails. Am. J. Infect. Control 1989, 17, 340-344. [CrossRef]

75. Hinkelbein, J.; Koehler, H.; Genzwuerker, H.V.; Fiedler, F. Artificial acrylic finger nails may alter pulse oximetry measurement. Resuscitation 2007, 74, 75-82. [CrossRef] [PubMed]

76. Edelist, G. Acrylic nails and pulse oximemtry. Anesth. Analg. 1995, 81, 884-885. [CrossRef] [PubMed]

77. Peters, S.M. The effect of acrylic nails on the measurement of oxygen saturation as determined by pulse oximetry. J. Am. Assoc. Nurse Anesth. 1997, 65, 361-363.

78. Gil, J.A.; DeFroda, S.; Reid, D.; Mansuripur, P.K. Closed traumatic finger tip injuries in patients with artificial nails: removal of UV gel and acrylic nails. Am. J. Emerg. Med. 2016, 34, 335-337. [CrossRef] [PubMed]

79. Dainichi, T.; Omori, M.; Hamada, M.; Hosokawa, C.; Moroi, Y.; Hashimoto, T.; Furue, M. Successful treatment of nail bed hypoplasia after nail loss by acrylic nail. Dermatol. Surg. 2008, 34, 984-985. [PubMed]

80. Purcell, E.M.; Hussain, M.; McCann, J. Fashionable splint for nailbed lacerations: The acrylic nail. Plast. Reconstr. Surg. 2003, 112, 337-338. [CrossRef] [PubMed] 
81. Kerai, L.V.; Hilton, S.; Murdan, S. UV-curable gel formulations: Potential drug carriers for the topical treatment of nail diseases. Int. J. Pharm. 2015, 492, 177-190. [CrossRef] [PubMed]

82. Quach, T.; Gunier, R.; Tran, A.; Von Behren, J.; Doan-Billings, P.A.; Nguyen, K.D.; Okahara, L.; Lui, B.Y.; Nguyen, M.; Huynh, J.; et al. Characterizing workplace exposures in Vietnamese women working in California nail salons. Am. J. Public Health 2011, 101, S271-S276. [CrossRef] [PubMed]

83. Kanerva, L.; Estlander, T. Allergic onycholysis and paronychia caused by cyanoacrylate nail glue, but not by photobonded methacrylate nails. Eur. J. Dermatol. 2000, 10, 223-225. [PubMed]

84. Koppula, S.V.; Fellman, J.H.; Storrs, F.J. Screening allergens for acrylate dermatitis associated with artificial nails. Am. J. Contact Dermat. 1995, 6, 78-85. [CrossRef]

85. Ramos, L.; Cabral, R.; Goncalo, M. Allergic contact dermatitis caused by acrylates and methacrylates-a 7-year study. Contact Dermat. 2014, 71, 102-107. [CrossRef] [PubMed]

86. Savage, T.; Khan, A.; Loftus, B.G. Acetone-free nail polish remover pads: toxicity in a 9-month old. Arch. Dis. Child. 2007, 92, 371. [CrossRef] [PubMed]

87. Chevillotte, G.; Ficheux, A.S.; Morisset, T.; Roudot, A.C. Exposure method development for risk assessment to cosmetic products using a standard composition. Food Chem. Toxicol. 2014, 68, 108-116. [CrossRef] [PubMed]

88. Ramu, A.; Rosenbaum, J.; Blaschke, T.F. Disposition of acetone following acute acetone intoxication. West. J. Med. 1978, 129, 429-432. [PubMed]

89. Brown, J.J.; Nanayakkara, C.S. Acetone-free nail polish removers: Are they safe? Clin. Toxicol. 2005, 43, 297-299. [CrossRef]

90. Rambourg-Schepens, M.O.; Buffet, M.; Durak, C.; Mathieu-Nolf, M. Gamma butyrolactone poisoning and its similarities to gamma hydroxybutyric acid: Two case reports. Vet. Hum. Toxicol. 1997, 39, 234-235. [PubMed]

91. Hornfeldt, C.S.; Rabe, W.H. Nitroethane poisoning from an artificial fingernail remover. J. Toxicol. Clin. Toxicol. 1994, 32, 321-324. [CrossRef] [PubMed]

92. Patra, S.; Sikka, G.; Khaowas, A.K.; Sheen, S.; Henretig, F.M. Rebound severe methemoglobinemia from ingestion of a nitroethane artificial-fingernail remover. J. Pediatr. 1995, 126, 819-821.

93. Patra, S.; Sikka, G.; Khaowas, A.K.; Kumar, V. Successful intervention in a child with toxic methemoglobinemia due to nail polish remover poisoning. Indian J. Occup. Environ. Med. 2011, 15, 137-138. [CrossRef] [PubMed]

94. Potter, J.L.; Krill, C.E., Jr.; Neal, D.; Kofron, W.G. Methemoglobinemia due to ingestion of $\mathrm{N}, \mathrm{N}$-dimethyl- $p$-toluidine, a component used in the fabrication of artificial fingernails. Ann. Emerg. Med. 1988, 17, 1098-1100. [CrossRef]

95. Viegas, J. Profile of Beatrice H. Hahn. Proc. Natl. Acad. Sci. USA 2013, 110, 6613-6615. [CrossRef] [PubMed]

96. Shepherd, G.; Grover, J.; Klein-Schwartz, W. Prolonged formation of methemoglobin following nitroethane ingestion. J. Toxicol. Clin. Toxicol. 1998, 36, 613-616. [CrossRef] [PubMed]

97. Caravati, E.M.; Litovitz, T.L. Pediatric cyanide intoxication and death from an acetonitrile-containing cosmetic. J. Am. Med. Assoc. 1988, 260, 3470-3483. [CrossRef]

98. Geller, R.J.; Ekins, B.R.; Iknoian, R.C. Cyanide toxicity from acetonitrile-containing false nail remover. Am. J. Emerg. Med. 1991, 9, 268-270. [CrossRef]

99. Mueller, M.; Borland, C. Delayed cyanide poisoning following acetonitrile ingestion. Postgrad. Med. J. 1997, 73, 299-300. [CrossRef] [PubMed]

100. Turchen, S.G.; Manoguerra, A.S.; Whitney, C. Severe cyanide poisoning from the ingestion of an acetonitrile-containing cosmetic. Am. J. Emerg. Med. 1991, 9, 264-267. [CrossRef]

101. US Food and Drug Administration. Scheduling of Drugs Under the Controlled Substances Act-GHB. Available online: https:/ /www.fda.gov/newsevents/testimony/ucm115087.htm (accessed on 1 June 2017).

102. Dikshith, T.S.S. Handbook of Chemicals and Safety; CRC Press: Florida, FL, USA, 2011.

103. Senthilkumaran, S.; Balamurgan, N.; Menezes, R.G.; Thirumalaikolundusubramanian, P. Nail polish remover poisoning: What caused methemoglobinemia? Indian J. Occup. Environ. Med. 2012, 16, 91. [CrossRef] [PubMed]

104. Linden, C.H.; Scudder, D.W.; Dowsett, R.P.; Liebelt, E.L.; Woolf, A.D. Corrosive injury from methacrylic acid in artificial nail primers: Another hazard fingernail products. Pediatrics 1998, 102, 979-984. [CrossRef] [PubMed] 
105. Woolf, A.; Shaw, J. Childhood injuries from artificial nail primer cosmetic products. Am. J. Dis. Child. 1998, 152, 41-46. [CrossRef]

106. Helsing, P.; Austad, J.; Talberg, H.J. Onycholysis induced by nail hardener. Contact Dermat. 2007, 57, $280-281$. [CrossRef] [PubMed]

107. De Wit, F.S.; de Groot, A.C.; Weyland, J.W.; Bos, J.D. An outbreak of contact dermatitis from toluenesulfonamide formaldehyde resin in a nail hardener. Contact Dermat. 1988, 18, 280-283. [CrossRef] [PubMed]

108. Daly, B.M.; Johnson, M. Pterygium inversum unguis due to nail fortifier. Contact Dermat. 1986, 15, $256-257$. [CrossRef] [PubMed]

109. Belsito, D.V. Contact dermatitis to ethyl-cyanoacrylate-containing glue. Contact Dermat. 1987, 17, $234-236$. [CrossRef] [PubMed]

110. Minamoto, K. Allergic contact dermatitis from two-component acrylic resin in a manicurist and a dental hygienist. J. Occup. Health 2014, 56, 229-234. [CrossRef] [PubMed]

111. Teik-Jin Goon, A.; Bruze, M.; Zimerson, E.; Goh, C.L.; Isaksson, M. Contact allergy to acrylates/methacrylates in the acrylate and nail acrylics series in southern Sweden: simultaneous positive patch test reaction patterns and possible screening allergens. Contact Dermat. 2007, 57, 21-27. [CrossRef] [PubMed]

112. Alaves, V.M.; Sleeth, D.K.; Thiese, M.S.; Larson, R.R. Characterization of indoor air contaminants in a randomly selected set of commercial nail salons in Salt Lake County, Utah, USA. Int. J. Environ. Health Res. 2013, 23, 419-433. [CrossRef] [PubMed]

113. Hiipakka, D.; Samimi, B. Exposure of acrylic fingernail sculptors to organic vapors and methacrylate dusts. Am. Ind. Hyg. Assoc. J. 1987, 48, 230-237. [CrossRef] [PubMed]

114. Park, S.A.; Gwak, S.; Choi, S. Assessment of occupational symptoms and chemical exposures for nail salon technicians in Daegu City, Korea. J. Prev. Med. Public Health 2014, 47, 169-176. [CrossRef] [PubMed]

115. LoSasso, G.L.; Rapport, L.J.; Axelrod, B.N.; Douglas, W.R. Neurocognitive sequelae of exposure to organic solvents and (meth)acrylates among nail-studio technicians. Neuropsychiatry Neuropsychol. Behav. Neurol. 2002, 15, 44-55.

116. LoSasso, G.L.; Rapport, L.J.; Axelrod, B.N. Neuropsychological symptoms associated with low-level exposure to solvents and (meth) acrylates among nail technicians. Neuropsychiatry Neuropsychol. Behav. Neurol. 2001, 14, 183-189.

117. Garcia, E.; Sharma, S.; Pierce, M.; Bhatia, S.; Argao, S.T.; Hoang, K.; Quach, T. Evaluating a county-based healthy nail salon recognition program. Am. J. Ind. Med. 2015, 58, 193-202. [CrossRef] [PubMed]

118. Ursberg, A.M.; Bergendorff, O.; Thorsson, A.C.; Isaksson, M. Is there a good in vivo method to show whether gloves are sufficiently protective when a nail technician is exposed to (meth) acrylates? An in vivo pilot study. Contact Dermat. 2016, 75, 62-65. [CrossRef] [PubMed]

119. Gosavi, S.S.; Gosavi, S.Y.; Alla, R.K. Local and systemic effects of unpolymerised monomers. Dent. Res. J. 2010, 7, 82-87.

120. Agency for Toxic Substances and Disease Registry. Toxic Substance Portal-Toluene. ATSDR: Atlanta, GA, USA, 2014.

(c) 2017 by the authors. Licensee MDPI, Basel, Switzerland. This article is an open access article distributed under the terms and conditions of the Creative Commons Attribution (CC BY) license (http:// creativecommons.org/licenses/by/4.0/). 